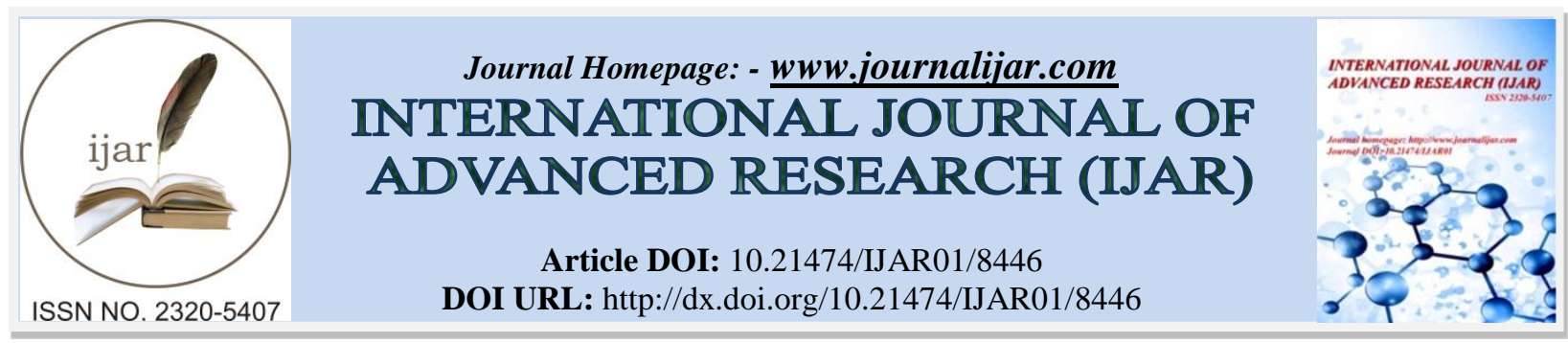

RESEARCH ARTICLE

\title{
EPIDEMIOLOGY OF SEVERE BURNS ADMITTED IN PEDIATRIC INTENSIVE CARE UNITS.
}

\author{
Hayate Bouchtalla ${ }^{1}$, Charaf Ait Elharda ${ }^{1}$, Samia Idrissi Kaitouni ${ }^{1}$, Souhail Errafia ${ }^{1}$, Naizha Haimeur ${ }^{1}$, \\ Youssef Mouaffak ${ }^{1}$,Said Younous ${ }^{1}$, Mariam Quaboul ${ }^{2}$, Abdelkoddous Bhihi ${ }^{2}$, Moulay Driss El Amrani ${ }^{2}$ and \\ Yassine Benchamkha ${ }^{2}$. \\ 1. Pediatric intensive care unit - Mother-Child Hospital - Mohammed VI University Hospital - Cadi Ayyad \\ University - Marrakech, Morocco. \\ 2. Aesthetic Plastic Surgery Service and Burns - Mohammed VI University Hospital - Cadi Ayyad University - \\ Marrakech, Morocco.
}

\section{Manuscript Info}

\section{Manuscript History}

Received: 20 November 2018

Final Accepted: 22 December 2018

Published: January 2019

Key words:-

burn; children; nursing; infections; prevention; scalds.

\section{Abstract}

Introduction:Burn injuries are one of the top 10 causes of unintentional deaths in children younger than 14 years old. Most pediatric burns are minor, but children with severe burns have higher mortality than nonelderly adults with similar burns.

Aims and objectives:To study the epidemiological particularities and the prognostic factors in order to prevent these accidents and to improve the future of the patients.

Materials and methods:This study is retrospective and descriptive. It covers all the children burned and hospitalized in the pediatric intensive care unit of the Mohammed VI University Hospital of Marrakech during the period from January 2009 to December 2017. The criteria for inclusion are any burns covering more than $15 \%$ of a skin surface, any burns in a deep surface exceeding $5 \%$, when a burn is cervicofacial, or when the burn is responsible for circular lesions.

Findings and discussion:401 cases were collected during this period mentioned above. The incidence of severe burns in children was $5.6 \%$. The most affected age group is between 0 and 4 years old with a male predominance $(63 \%)$. Children from rural regions were more dominant (61\%). $40 \%$ of the patients were admitted between 3 and 12 hours after the incident. $89 \%$ of the incidents occurred at home. Scalding was the most common mechanism (70\%). Inpatient admission was done in 59\% of cases via pediatric emergencies. The average area of skin burned was $18.8 \%$. The most common location was limb involvement (35\%) with superficial to intermediate second degree burns predominating (51\%). Therapeutically, apart from patients admitted late (22\%), all the others benefited from rehydration according to the Carvajal scheme. All the patients also benefited from multimodal analgesia (Morphine Paracetamol - Ibuprofen) care performed by the plastic surgery team, and a mostly enteral diet (91\%) introduced within an average of 1.7 days. In addition, we noted the occurrence of various ionic and metabolic disorders in $75 \%$ of cases, anemia in $67 \%$ of patients. The infection reached $43 \%$ of children burned. The mortality rate was
Corresponding Author:-Hayate Bouchtalla.

Address:-Pediatric intensive care unit - Mother-Child Hospital - Mohammed VI University

Hospital - Cadi Ayyad University - Marrakech, Morocco. 
$6.38 \%$, and the average duration of hospitalization was 5.8 days. In our context, some elements such as the age of the patient being less than 4 years old, flame burn, the burned skin area exceeding $30 \%$, defective initial management, delayed admission and infection occurrence, can be factors of poor prognosis.

Conclusion:Our data demonstrates the importance of developing a program for the prevention of pediatric scalds by educating family members and raising their awareness of the danger. With present studies, the knowledge about the occurrence of injuries in scald accidents in children has become deeper. This knowledge may contribute to more individual adept child accident prevention program that could be used in the children health care.

Copy Right, IJAR, 2018,. All rights reserved.

\section{Introduction:-}

Severe burn injuries represent a significant problem worldwide. More than 1 million burn injuries occur annually in the United States. Although most of these burn injuries are minor, approximately $10 \%$ of burn patients require admission to a hospital or a major burn center for appropriate treatment every year ${ }^{(1)}$. Sweden has the lowest accident mortality for children in the world (SOU 2002:99, IRTAD 2003). The mortality rate for accidents in Sweden in 1999 was 22/100 000 children (World Health Organization 2003) ${ }^{(2)}$. Recent reports have revealed a 50\% decline in burn-related deaths and hospital admissions in the USA over the last 20 years. This is mainly due to effective prevention strategies, decreasing the number and severity of burns ${ }^{(3)}$. Burn injuries are often a serious tragedy for both parents and children. This is caused by the pain and the trauma of dressings, procedures, hospitalization and emotional adjustments in an immature child, the mortality risk, the long-term rehabilitation, and the cosmetic disfigurement ${ }^{(2)}$.Advances in therapeutic strategies, including advances in resuscitation, wound coverage, better support of hypermetabolic response to injury, more appropriate infection control and improved treatment of inhalation injury, have further improved the clinical outcome of this unique patient population over the past years. However, severe burns remain a devastating injury affecting nearly every organ system and leading to significant morbidity and mortality ${ }^{(4)}$.

\section{Patients and methods:}

\section{Study area and population}

This study was performed in Marrakesh, a city with 839,296 inhabitants (2017), in Morocco during the period from January 2009 to December 2017. The city has 68 Health Centers and one University Hospital. Among other specialties, the hospital also has a department for pediatric intensive care for burn injuries with a department for plastic surgery. Parents of children with burn injuries could voluntarily choose to consult either the emergency unit at the hospital or the Health Center in their neighborhood.

\section{Data collecting}

The data were collected from medical records in a retrospectively designed study. All emergency incoming patients at the University Hospital were recorded according to age, sex, and diagnosis. All the burn injuries in children found in these registers during the period from January 2009 to December 2017 were compiled through medical records by one of the authors (AC). The internal dropout was due to the fact that not all of the questions could be answered through the medical records. Children admitted during the study period with any type of burn-related injury were selected for review. Data on the burn-injured children consulting the Health Centers were collected through the diagnosis registration. All medical records of the children were registered for sex, age, and identity of the parents.

\section{Definitions}

Not only body site, extent and depth of injuries that were investigated but causes and location of injuries were investigated too. The extent of the injuries was classified in two groups: $<2$ and $>2 \%{ }^{(5)}$. The depth of the injuries was categorized in three degrees: degree 1 was red but intact skin, degree 2 was blisters, and degree 3 was when parts of the skin needed to be taken away for recovery ${ }^{(6)}$. 


\section{Findings}

\section{Frequency}

During the study period, the overall number of hospitalizations for pediatric resuscitation of Mohammed VI

University Hospital of Marrakech was 6479 children. Among the 401 patients admitted for management of severe burns, an incidence of $6.18 \%$ recall that a continuous and significant increase in the incidence of severe burns has been noted with a rate increased from 1.2\% in 2009 to $7.6 \%$ in 2017. Recent data from the hospitalized children's registry at our training indicate that 75 children were admitted during the year 2016.

\section{Breakdown by year}

The number of burned children admitted to the service is increasing relatively during the end of year and summer holidays, as well as during the month of Ramadan.

Age

The median age was 2.5 years and children under 4 had $62 \%$ of all hospitalizations. We noted a predominance of the age between 2 to 3 years (23\%), followed by that between 1 to 2 years (19\%).

Sex

The sex ratio was 1.7 with a total of 64 boys $(63 \%)$.

\section{Distribution according to the origin}

Among our patients, $61 \%$ came from rural areas.

\section{Location}

In $89 \%$ of cases, the accident occurred at home. The rest took place during the game in the street, at school or, on the occurrence (occasion has a positive vibe) of a road accident.

\section{Etiology}

Scalding, as a thermal burn, alone was accounted for $70 \%$ of mechanisms, while the flame was incriminated in $30 \%$ of the cases.

\section{Causal agent}

Multiple agents have been identified (Fig.1). Thermal scald burns are caused by hot water ( $42 \%$ of all agents) and flame thermal burns are related to manipulation, leakage or explosion of gas cylinders ( $23 \%$ of all agents).

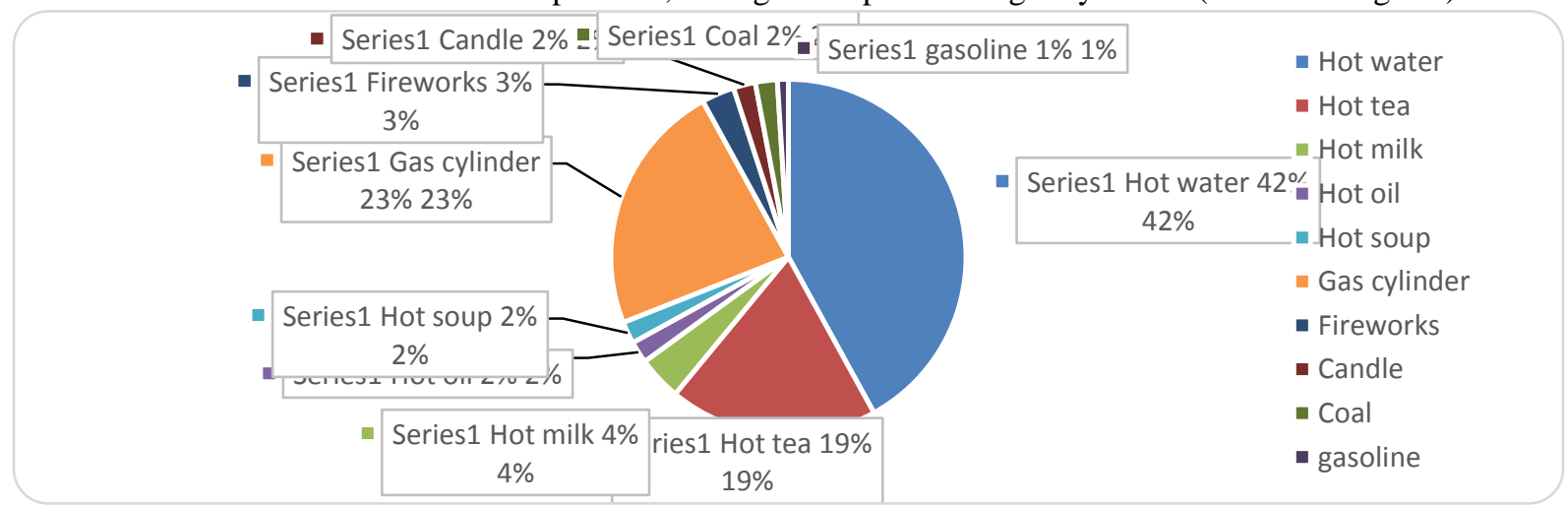

Figure 1:-causal agent Scalds were the most common type of burn

\section{Admission deadline}

We noticed that there is a significant difference between the admission deadlines between the patients (the minimum value estimated at 30 minutes, while the maximum value was 22 days after the burn (Fig.2)). 


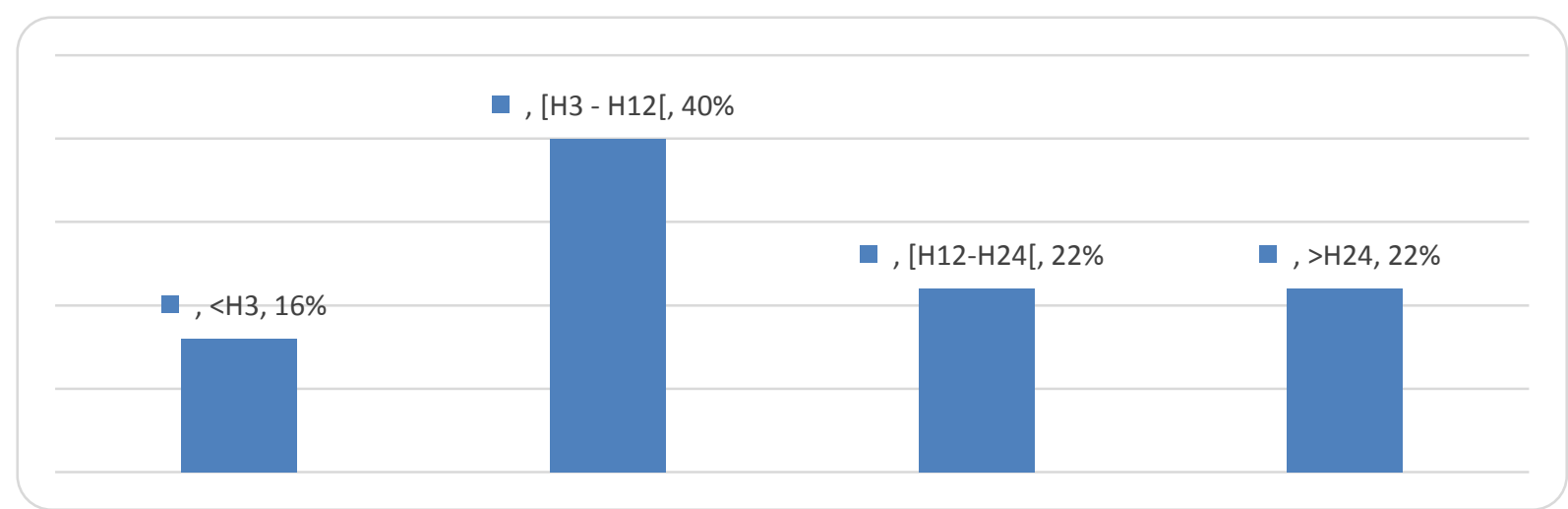

Figure 2:-Admission deadline The majority of patients were admitted between $\mathrm{H} 3$ and $\mathrm{H} 12$

\section{Reference structure}

$67 \%$ of the patients were admitted after their reception in a health facility of our university hospital: $59 \%$ consulting directly to pediatric emergencies, $8 \%$ via plastic surgeons, while 33\% of patients were referred by level 2 .

\section{Localization of the burn}

The involvement of the limbs takes the first position (35\%) for the localization of the lesions, followed by the trunk and the face. The neck and the perineum come last (10\% and 6\% successively). We must point out that in $75 \%$ of patients; the burn has involved two or more areas. (Fig 3)

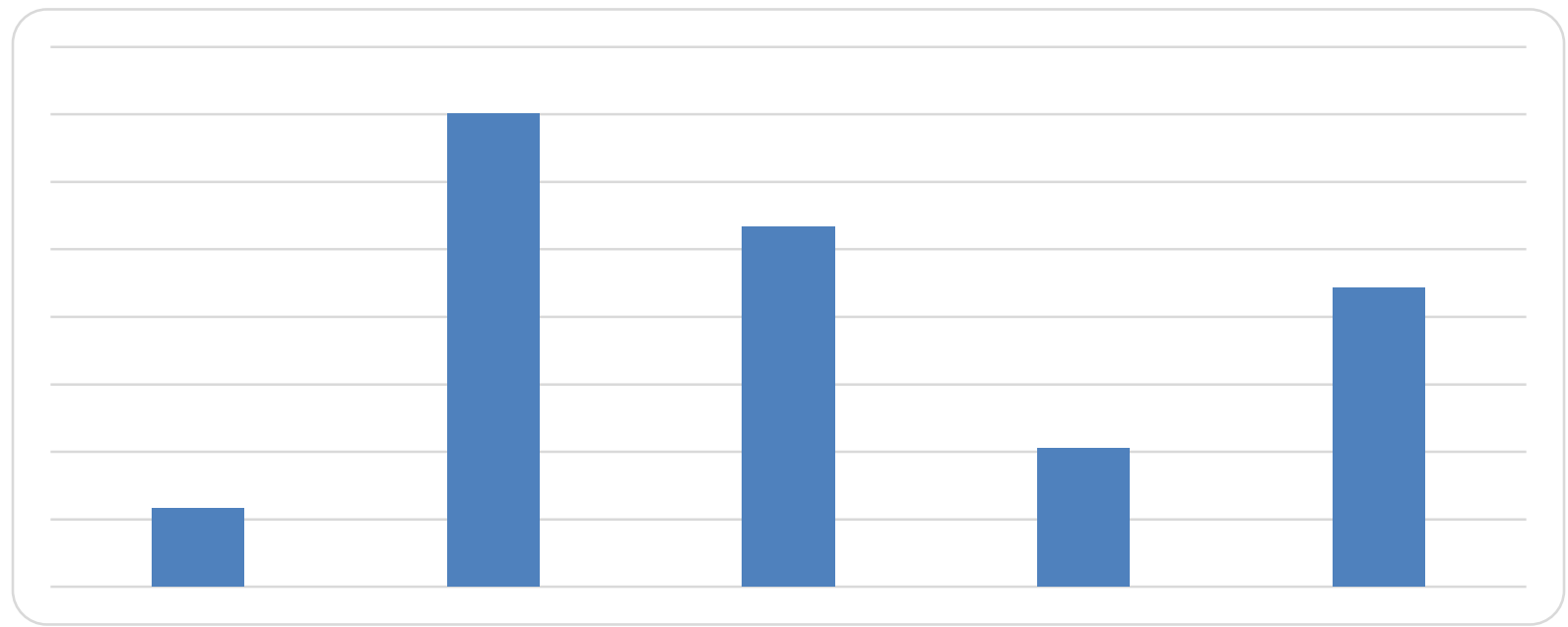

Figure 3:-Localization of the burn

\section{Burn size}

The mean TBSA in our patients was $18.8 \%$ and $74 \%$ of patients were admitted with a TBSA greater than $10 \%$, of which $13 \%$ exceeds $30 \%$. (Fig 4) 


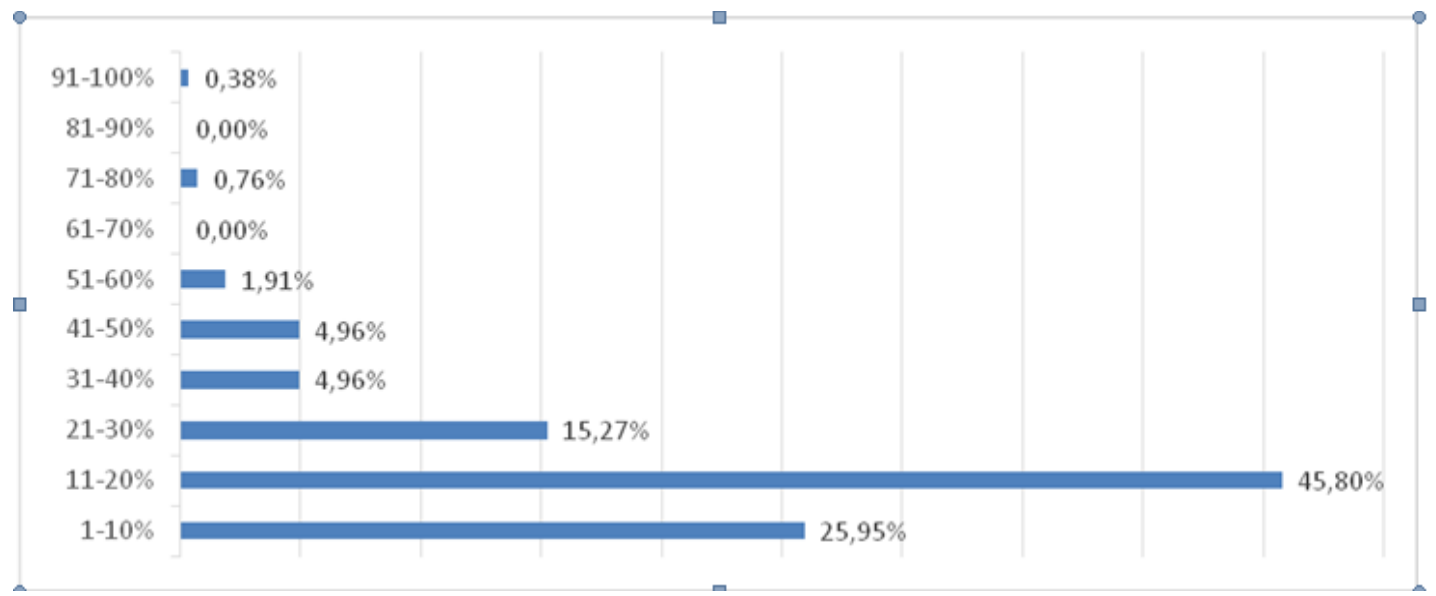

Figure 4:-Burn size The TBSA was less than $30 \%$ in $90 \%$ of children

\section{Predominance}

In our patients, we noted a predominance of second-degree burns superficial and deep (51\% of cases), followed by superficial

2nd degree burns (Fig.5).

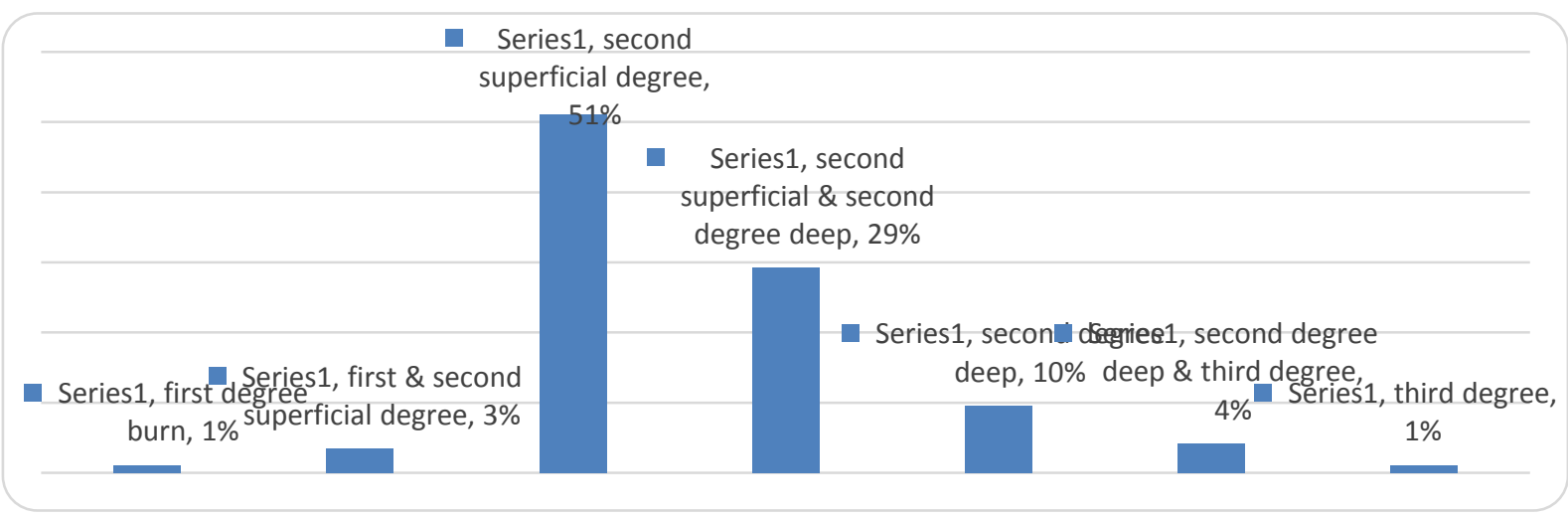

Figure 5:-Predominance

\section{Initial treatment}

It was given to $45 \%$ of the burned children at the scene of the incident. The treatment was traditional in $17 \%$ of cases (application of Henna, eggs, tomatoes, toothpaste, herbs of unspecified nature ...), outpatient in $21 \%$ of cases (dressing, prescription ...), and hospital in $62 \%$ of cases (peripheral venous, dressing, incisions, analgesia ...).

\section{Medical care in a specialized environment:}

\section{Vascular approach}

1. All children admitted to our training have had a peripheral venous pathway. A central venous line was established in $30 \%$ of patients with an average delay of 1.38 day. The femoral way was the most used (65\%), unlike the jugular way (35\%). The average duration of use was 6.78 days.

2. The arterial catheter was used in 33 patients with an average delay of 1.2 days after admission of the patient. The average duration of use of the arterial catheter was 6.16 days.

\section{Volume expansion}

Except patients admitted to J2 burn and more (estimated at 22\%). All others patients have benefited from volume expansion according to the formula of CARVAJAL. The solute used for filling was $0.9 \%$ saline. 


\section{Catecholamines}

44 patients $(17 \%)$ were placed on catecholamines, namely Dopamine, Noradrenaline, Adrenaline and Dobutamine. These were used alone or in association according to the situations.

\section{Respiratory resuscitation}

In addition to oxygenation, nasal canula, or face mask which were used in all patients, 47 of them had received mechanical ventilation (18\%). The average duration of this ventilatory assistance was 5.25 days, and 9 patients (3\% of ventilated) had developed pneumopathy acquired under mechanical ventilation.

\section{Analgesia}

Many molecules have been used to relieve pain in our patients: Paracetamol, Codeine, Ibuprofen, Morphine Hydrochloride, Nalbuphine, and Fentanyl.

\section{Gastric protection}

As part of the protection against stress ulcer or duodeno-gastritis, all our patients received an IPP or an Anti-H2.

\section{Nutrition}

In the case of our patients, the diet was enteral (direct oral or by nasogastric tube) in $91 \%$, and parenteral in only $9 \%$ of cases. The average time of introduction of enteral feeding is calculated at 1.7 days ( 1 day and 17 hours).

\section{Evolution:}

Metabolic disorders

During their hospitalization, the patients were presented with several hydroelectrolytic disorders (Fig.6):

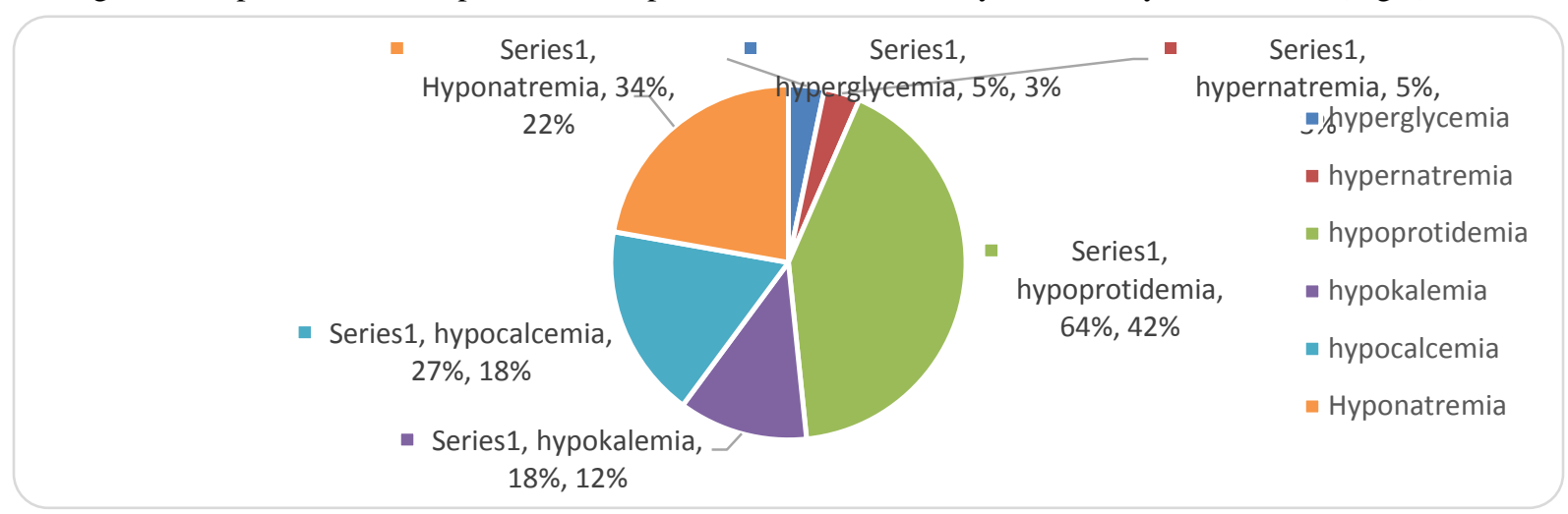

Figure 6: Metabolic disorders

\section{Hematological disorders}

Thrombocytopenia and haemostasis disorders:

Amongst our patients, 3 have developed thrombocytopenia (1.1\%). A CIVD has been reported in 8 patients (3\%).

\section{Anemia}

1. It was found in 174 patients (67\% of cases). It was hypochromic microcytic in $95 \%$ of cases, normochromic normochromium in $4 \%$, and normochromic macrocytic in $1 \%$.

2. Transfusion was performed in 36 patients (14\%), $50 \%$ of whom with hemoglobin levels below $8 \mathrm{~g} / \mathrm{dl}, 14 \%$ by fresh plasma frozen in prothrombin rate, and $36 \%$ albumin for hypo albuminemia less than $20 \mathrm{~g} / \mathrm{l}$. Iron supplementation was used in 141 patients (54\%), and oral iron was privileged.

\section{Infection}

Of the hospitalized patients, infection was reported in 176 patients (43\%). The infection was reported in 50\% of cases before D4, and in $15 \%$ of cases after D4. Recall that approximately $65 \%$ of children infected early had previously received home care or external care, and that one-third of the children admitted to our training had already local and / or general signs of infection. 
Cutaneous infection complicated or not bacteremia (whether clinical or documented) was reported in $93 \%$ of cases. The pulmonary infection in $5 \%$ followed by urinary tract infection in $2 \%$ of cases.

Fever, sometimes accompanied by chills, septic shock, local signs, and especially the change in the behavior of the child were indicative of infection in $90 \%$ of the cases (Fig 7). The kinetics of white blood cells and C-reactive protein, blood cultures and skin swabs were contributing to the diagnosis of infection in $93 \%$ of cases.

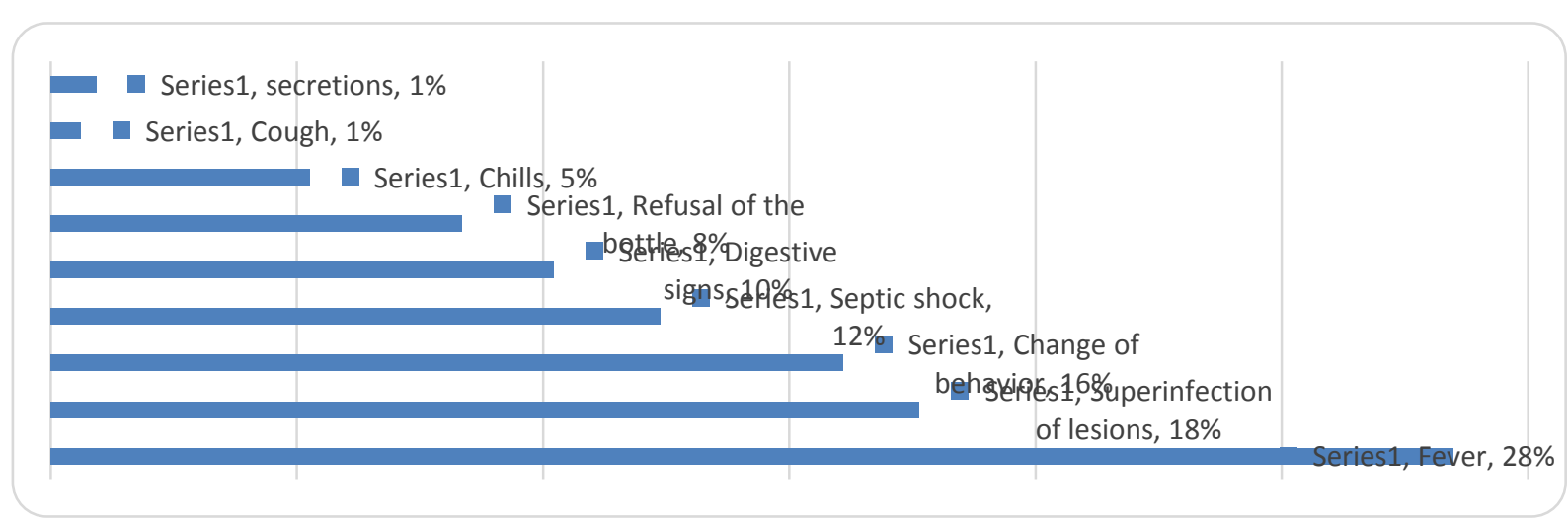

Figure 7:-Infection indicators

The infection was documented in $31 \%$ of cases. These are quite varied species presented by GPC in $54 \%$ of cases (Staphylococci (40\%) - Streptococci (8\%) -Entococcus (6\%)) and BGN in 32\% of cases (table 1). Fungal infections have been authenticated in $5 \%$ of cases with exclusive isolation of Candida non albicans. We must point out that the microorganisms most frequently isolated in our training, are SAMS, SAMR, and Pseudomonas aeruginosa.

$52.6 \%$ of children have received an antibiotic therapy. It was curative at 114 Patients and preventives in 23 patients (after a surgical procedure such as a discharge incision or fasciotomy, an osteosynthesis). Multiple antibiotics were used. The Ceftazidime-Amikacin combination was used in $66 \%$ of the cases, followed by Amoxicillin-clavulanic acid in $19 \%$ of cases. Glycopeptides were introduced from the outset in children admitted to severe infectious tables and a fortiori when they had previously received care in other health facilities. The antibiotic therapy was adapted secondarily in $26 \%$ of cases. As such, a therapeutic escalation (Carbapenem - Glycopeptides - Antifungals) was noted in 20 patients and de-escalation in 15 children.

\begin{tabular}{|c|c|c|c|}
\hline \multicolumn{3}{|r|}{ Germs } & \multirow{2}{*}{$\begin{array}{r}\text { Percentage } \\
23 \%\end{array}$} \\
\hline \multirow{6}{*}{ GPC $(54 \%)$} & \multirow{3}{*}{ Staphylococcus } & SAMS & \\
\hline & & SAMR & $10 \%$ \\
\hline & & SCN & $7 \%$ \\
\hline & Enterococcus & EnterococcusFaecalis & $6 \%$ \\
\hline & \multirow{2}{*}{ Streptococcus } & Streptococcus bêta Hémolyticpyogène & $6 \%$ \\
\hline & & StreptococcusPneumoniae & $2 \%$ \\
\hline \multirow{6}{*}{\multicolumn{2}{|c|}{ GNB $(32 \%)$}} & Pseudomonas Aeruginosa & $9 \%$ \\
\hline & & Acintobacterbaumannii & $6 \%$ \\
\hline & & Escherichia Coli & $6 \%$ \\
\hline & & Klebsiella & $5 \%$ \\
\hline & & Enterobacter Cloacae & $4 \%$ \\
\hline & & Serratia & $2 \%$ \\
\hline \multicolumn{2}{|c|}{ Candida $(7 \%)$} & Candida non Albicans & $5 \%$ \\
\hline \multicolumn{3}{|r|}{ Others } & $7 \%$ \\
\hline
\end{tabular}

Table 1:-species of germs

\section{Surgical complications}

The compartment syndrome is a medico-surgical emergency that has been reported at 25 diseased, complicating especially the circular lesions and those localized at the level of the hands. Cutaneous necrosis is a complication that has been reported in 17 patients, motivating necrosectomy in 7 patients and amputation in two. The compartment 
syndrome was observed in 25 patients, and complicated of amputation in 7 cases. We must note that a peptic peel ulcer was reported in 3 ill patients. In one child, it was complicated by perforation (peritonitis) laparotomy, and in the other he was complicated by haemorrhagic shock.

\section{Duration of hospitalization}

The average length of stay was estimated at 4.9 days.

\section{Becoming}

In our study, $93.7 \%$ of burned children had a favorable evolution. $55 \%$ of them were transferred secondarily to the service of infant surgery or plastic surgery for complement of care while $36 \%$ of the children, were declared outgoing from the outset, in consultation with the surgical team, towards the consultation of specialized for external care, change of dressing and follow-up.

Of our patients, 25 died (or $6.3 \%$ ). We noticed that among the serious burned children, deceased:

1. $60 \%$ have an age $<4$ years.

2. $63 \%$ are boys and $38 \%$ are girls.

3. $50 \%$ of burns are caused by the flame, and $37.5 \%$ by hot water.

4. $58 \%$ were admitted after at least 6 hours of the accident, about half of which was 12 hours.

5. $60 \%$ have a SCB exceeding $30 \%$.

\section{Prevention}

It is a long-term process to prevent child accidents. This long-term process cooperates to motivate the parents to take precautions to prevent accidents. The responsibilities of the landlords, concerning the environmental risks in flats, are well regulated in Morocco but not always so well known by the citizens. Campaigns aimed to educate the public about environmental risks in children can be advertized on the airwave media, on billboard posters, at nursery schools and in the Child Health Services.

\section{Discussion:-}

1. In this study $72 \%$ of the burn-injured children were under four years old. This age group is also seen as the most common age group for burn injuries in other studies ${ }^{(2,7)}$. Children aged under three often stay near their parents while they are cooking, and therefore they are more exposed to burn risks ${ }^{(2)}$. Almost all of the children $(96 \%)$ in the present study had their parent close by when the accident occurred. Many of those accidents could have been avoided as they were caused by preventable events ${ }^{(2)}$. The incidence of hospitalization for pediatric burns is highest in Africa, lowest in the Americas, and with similar rates in Europe, the Middle East and Asia, which bears over half of the world's pediatric burn cases because of its population size ${ }^{(8)}$. A greater proportion of the pediatric cases in this study were males with a male to female ratio of 1.7. The later is higher than that of other reports ${ }^{(9)}$. The majority of pediatric cases present in our population were local rural residents. The higher incidence may be related to the fact that supervision, security, and facilities in rural families are generally poorer than those found in urban families ${ }^{(10)}$. Therefore, prevention programs focused on pediatric burns should be targeted to rural populations ${ }^{(11)}$.

2. Previous studies have shown that burn injuries in children are most frequently scalds caused by hot liquid, especially hot coffee or tea ${ }^{(2)}$. Results of this study also demonstrate that almost $70 \%$ of the pediatric burns were a result of scalding that occurred at home. An earlier report from the Middle East has shown much higher percentages ${ }^{(12)}$. Other studies have shown that hot baths were the most frequently observed causes of scalds ${ }^{(13)}$. Furthermore, some habits should be changed in order to prevent burns. For example, bath water for infants is typically prepared by first pouring boiling water into the basin and then adding cold water. To prevent burns from children accidentally falling into the basin, the order should be reversed ${ }^{(14)}$.

3. Although the majority of pediatric burns can be avoided by preventing scalding, flame and electrical burns should not be ignored because of the poorer associated prognosis, such as amputation, scar hyperplasia and physical dysfunction. As the age of the patients increased, the proportion of burns due to scalding decreased while flame and electrical injuries markedly increased. This is consistent with findings from a study in India ${ }^{(15)}$.

4. As expected we found that increased burn size leads to increased risk of mortality among children. This is a finding similar to other studies results. ${ }^{(16,17,18)}$

5. Only eight out of 25 deaths were caused by burns of less than $30 \%$ TBSA. These eight non-survivors only show that children can die from small burns too if there are associated to risk factors like sepsis. 
6. It was also found that children less than 4 years had a higher risk of death, regardless of burn size. Whether the increased mortality is just due to the increased number of admissions in that age group or whether the younger age predisposes them to increased mortality is not clear. The reasons which may predispose the younger ones to increased mortality may be due to increased surface area which leads to increase in fluid requirements and immaturity of the immune system which may predispose them to sepsis and its related complications ${ }^{(18)}$. Sepsis was a significant predictor of mortality. The cause of sepsis may be related to two factors. Poor socio-economic status with low hygienic standards may be one of the reasons and the other may be a delay in primary excision and grafting.

\section{Conclusion:-}

Burns are among the most traumatic of injuries and can impose significant psychological, educational, social, and future occupational limitations to a young child.

Government agencies, teachers, medical personnel, and the media all have the opportunity and responsibility to publicize burn prevention. The media, including newspapers, radio and television is a particularly effective mean and should be exploited for the dissemination of burn prevention knowledge concerning scalding from hot liquids and risks associated with flammable substances and electricity in high-risk environments (home) and populations (infants).

\section{Competing interests}

The authors declare that they have no competing interests.

\section{Authors' contributions}

All authors have made substantial contributions to all the following: H. BOUCHTALLA, M. Quaboul, Y. MOUAFFAK and S. YOUNOUS, were involved in the conception and design of the study, or acquisition of data, or analysing and interpretation of data. They were involved in drafting the article or revising it critically for important intellectual content. They were involved in the final approval of the version to be submitted.

\section{References:-}

1. Nguyen TT, Gilpin DA, Meyer NA, et al. Current treatment of severely burned patients. Ann Surg. 1996 Jan;223(1):14-25.

2. Anna Carlsson MSc, GiggiUde'n PhD, et al. Burn injuries in small children, a population-based study in Sweden. 4 March 2005. Journal of Clinical Nursing 15, 129-134

3. Wolf S. Critical Care in the Severely burned: organ support and management of complications. In: Herndon DN, editor. Total Burn Care. 3rd ed. Vol 2007. Saunders Elsevier; London:

4. Herndon DN, Tompkins RG. Support of the metabolic response to burn injury. Lancet. 2004 Jun 5;363(9424):1895-1902.

5. den Hertog PC, Blankendaal F \& Ten Hag SM (2000) Burn injuries in the Netherlands. Accident Analysis and Prevention 32, 355-364.

6. Freccero C, Svensson H, Kalhor S \& Larsson A (2000) Scalding injuries in immigrant families. Scandinavian Journal of Plastic and Reconstruction Surgery and Hand Surgery 34, 309-313.

7. Sheller JLP \&Thuesen B (1998) Scalds in children caused by water from electrical kettles: effect of prevention through information. Burns 24, 420-424.

8. Burd A, Yuen C. A global study of hospitalized paediatric burn patients. Burns. 2005;31:432-8. doi: 10.1016/j.burns.2005.02.016.

9. Tse T, Poon CH, Tse KH, Tsui TK, Ayyappan T, Burd A. Paediatric burn prevention: An epidemiological approach. Burns. 2006;32:229-34. doi: 10.1016/j.burns.2005.08.025.

10. Edelman LS. Social and economic factors associated with the risk of burn injury. Burns. 2007;33:958-65. doi: 10.1016/j.burns.2007.05.002.

11. Liu XH, Jiang N, Tan C, Yu ZB, Jiang YL. Clinical features and treatment of pediatric burn patients. J China Med Univ2006;35:107 [in Chinese].

12. Sharma PN, Bang RL, Al-Fadhli AN, Sharma P, Bang S, Ghoneim IE. Paediatric burns in Kuwait: Incidence, causes and mortality. Burns. 2006;32:104-11. doi: 10.1016/j.burns.2005.08.006. 
13. Ray JG (1995) Burns in young children: a study of mechanism of burns in children aged 5 years and under in the Hamilton, Ontario Burn Unit. Burns 21, 463-466.

14. Liu Y, Cen Y, Chen JJ, Xu XW, Liu XX. Characteristics of paediatric burns in Sichuan province: Epidemiology and prevention. Burns. 2012;38:26-31. doi: 10.1016/j.burns.2010.12.005.

15. Ramakrishnan KM, Sankar J, Venkatraman J. Profile of pediatric burns Indian experience in a tertiary care burn unit. Burns. 2005;31:351-3. doi: 10.1016/j.burns.2004.11.005.

16. Tompkins RG, Remensnyder JP, Burke JF, et al. Significant reduction in mortality for children with burns injuries through the use of prompt eschar excision. Ann Surg 1988;208:577-85.

17. Erickson EJ, Merrell SW, Saffle JR, et al. Differences in mortality from thermal injury between pediatric and adult patients. PediatrSurg 1991;26:821-5.

18. Ramakrishnan KM, Sankar J, Venkatraman J. Profile of pediatric burns Indian experience in a tertiary care burn unit. Burns. 2005;31:351-3. doi: 10.1016/j.burns.2004.11.005. 